\title{
Multiple factors are required for specific RNA cleavage at a poly(A) addition site
}

\author{
Gregory M. Gilmartin, ${ }^{1}$ Michael A McDevitt, and Joseph R. Nevins ${ }^{1}$ \\ Howard Hughes Medical Institute, Rockefeller University, New York, New York 10021 USA
}

\begin{abstract}
An SP6 RNA containing the adenovirus $5 \mathrm{~L} 3$ poly(A) site is processed efficiently in a HeLa cell nuclear extract to generate correct $3^{\prime}$ termini. Accurate $3^{\prime}$ processing has also been demonstrated for the adenovirus E2A and SV40 early poly(A) sites, although these are processed less efficiently than the L3 site. Efficient cleavage at the poly(A) site requires the presence of a $5^{\prime}$-cap structure, as well as the RNA sequence motifs previously shown to be necessary for $3^{\prime}$ processing in vivo, suggesting the presence and action of the appropriate factors in the nuclear extract. Fractionation of the nuclear extract has revealed a requirement for at least two distinct factors for cleavage at the L3 poly(A) site. One of these factors appears to possess an RNA component due to its sensitivity to micrococcal nuclease. The activity of this fraction is also sensitive to $\alpha$-Sm monoclonal antibody, indicating the presence of an snRNP essential for the cleavage reaction. Additional factors are required for the subsequent polyadenylation reaction, indicating the involvement of a multicomponent complex in the processing of an RNA at the poly(A) site.
\end{abstract}

[Key Words: Poly(A) addition site; RNA cleavage; snRNP; 3' processing]

Received September 4, 1987; revised version accepted March 30, 1988.

The production of a mammalian mRNA is a complex process involving a number of biochemical events (for review, see Nevins 1983). One of these events is an RNA processing reaction that generates the $3^{\prime}$ terminus of the pre-mRNA through an endonucleolytic cleavage of a precursor RNA, prior to the post-transcriptional addition of $\sim 200$ adenylic acid residues. The genomic site at which the cleavage and polyadenylation reactions occur has been termed the poly(A) site (Nevins 1984; Birnstiel et al. 1985). An understanding of the exact mechanism of the $3^{\prime}$-processing reaction takes on added importance when one considers the contribution that this event may make to the regulation of gene expression. In particular, for those transcription units that possess multiple poly(A) sites, the use of which results in different mRNAs, the alternative selection of one particular site can regulate the mRNA product of transcription (Nevins 1983; Leff et al. 1986). Immunoglobulin M (IgM) gene expression is a case in point (Blattner and Tucker 1984). IgM membrane and secreted RNAs, the relative levels of which change dramatically during the course of B-cell maturation, possess different 3'-terminal sequences, which are specified by two distinct poly/A) sites (Alt et al. 1980; Early et al. 1980; Rogers et al. 1980). Although it appears that several factors contribute to the regulation of IgM expression, one critical aspect is the changing efficiency of poly(A) site utilization (Galli et al. 1987, 1988).

Previous experiments, utilizing in vivo assays for poly(A) site function, have defined sequences that are

1Present address: Howard Hughes Medical Institute, Department of $\mathrm{Mi}$ crobiology and Immunology, Duke University Medical Center, POB 3054, Durham, North Carolina 27710 USA. critical for poly(A) site formation. These include the highly conserved AAUAAA element upstream of the cleavage site (Proudfoot and Brownlee 1976; Fitzgerald and Shenk 1981; Montell et al. 1983; Wickens and Stephenson 1984) and the less conserved GU-rich or U-rich element downstream of the cleavage site (Birnstiel et al. 1985; Gil and Proudfoot 1986; McDevitt et al. 1986). The presence of multiple genetic elements required for efficient cleavage suggests the involvement of multiple components in the processing reaction, as is clearly the case for the splicing of pre-mRNA. If one of these components is limiting under certain circumstances, regulated use of the poly(A) site could be achieved through the control of the level of the factor. Given the sequence diversity, it is attractive to speculate that a factor recognizing the essential downstream sequence element could participate in such regulation. Clearly, the identification and isolation of these factors is the crucial next step in defining the basis for poly(A) site formation and the regulation of the event.

Recent progress in the development of in vitro systems that faithfully process a pre-mRNA at a poly(A) site (Moore and Sharp 1985) and that recognize sequences demonstrated to be important in vivo (Hart et al. 1985b; Zarkower et al. 1986) offers the hope that the components of the system may be identified. We have investigated the process of cleavage at the adenovirus L3 poly(A) site in vitro by biochemical fractionation of nuclear extracts, which are active for $3^{\prime}$ processing. We demonstrate that multiple factors are indeed required for cleavage at the poly(A) site and that one of these factors appears to possess an RNA component, probably a small nuclear RNA (snRNA), analogous to the splicing of pre- 
mRNA (for review, see Maniatis and Reed 1987; Sharp 1987) and the 3 ' processing of histone pre-mRNA (Strub et al. 1984; Schaufele et al. 1986). It seems likely that this component may mediate sequence recognition in the pre-mRNA. The subsequent polyadenylation reaction requires additional factors. Thus, mRNA 3 '-end formation in eukaryotic cells occurs through the action of multiple distinct processing activities, similar to the splicing of pre-mRNAs.

\section{Results}

\section{Characteristics of $\operatorname{poly}(A)$ site cleavage in vitro}

To assay for poly(A) site cleavage, we have incubated a capped ${ }^{32}$ P-labeled SP6 RNA transcript, which contains a poly(A) site near the $3^{\prime}$ terminus, in a HeLa cell nuclear extract followed by direct analysis of the products in a polyacrylamide $/ 8 \mathrm{M}$ urea sequencing gel. The uncoupling of the cleavage and poly(A) addition reactions was accomplished by incubation in the presence of $3^{\prime}$ dATP (Moore et al. 1986), which blocks the heterogeneous addition of AMP residues that would obscure the products of cleavage. An analysis of the cleavage of SP6 precursor RNAs containing the adenovirus type 5 (Ad5) L3, Ad5 E2A, and SV40 early poly(A) sites is shown in Figure 1A. Cleavage of the L3 pre-mRNA in the presence of $3^{\prime}$ dATP yielded two RNA products of $\sim 117$ and 123 nucleotides in length, placing the $3^{\prime}$ ends at 14 and 20 nucleotides downstream of the L3 AAUAAA respectively. RNase protection assays of L3 RNA from Ad5-infected cells revealed the same two $3^{\prime}$ ends (data not shown). These two L3 cleavage products were also ob- served by Moore et al. (1986), although the downstream cleavage was more prominent in their studies. Each of the processing products of the other precursor RNAs was of the size expected for accurate cleavage at the respective poly(A) sites. Of interest is the large difference in the relative cleavage efficiency. Reproducibly, $\sim 50 \%$ of the $\mathrm{L} 3$ precursor is cleaved at the poly(A) site, whereas only $10-20 \%$ of the E2A precursor is properly cleaved, and no more than $5 \%$ of early SV40 precursor is processed. This difference in relative efficiency, also observed by Hashimoto and Steitz (1986), was reproducible and appears to reflect the efficiencies of the poly(A) sites when assayed in vivo (M.A. McDevitt and J.R. Nevins, unpubl.).

Through the in vivo analysis of an extensive set of mutations in the SV40 early poly(A) site, our previous work established a sequence element located between 5 and 18 nucleotides downstream of the poly(A) site (Hart et al. 1985; McDevitt et al. 1986), which was critical for efficient cleavage. The results of a direct assay for cleavage using different SV40 early pre-mRNAs are shown in Figure 1B. A precursor lacking wild-type sequences between +5 and $+18(\mathrm{SV} 40 /+5)$ was processed very inefficiently when compared to the precursor containing these sequences $(\mathrm{SV} 40 /+18)$. This was not simply an effect of truncation of the precursor because each of these RNAs possesses an additional 41 nucleotides of plasmid-encoded sequence beyond the SV40-specific sequence. Furthermore, cleavage was restored to the $+5 /+18$ deletion by the addition of a downstream element from the adenovirus E2A poly(A) site (SV40/ $+5 /+$ E2A). These results correlate well with the anal-

Figure 1. In vitro assays for cleavage at the L3, E2A and SV40 early poly(A) sites. $(A){ }^{32} \mathrm{P}$-labeled SP6 transcripts containing the Ad5, L3, E2A, or SV40 early poly(A) sites were incubated with a HeLa cell nuclear extract, and the products were analyzed on a $5 \%$ polyacrylamide gel. The dried gel was subjected to autoradiography for 12 or $36 \mathrm{hr}$, as indicated. Arrows indicate correctly processed transcripts. (B) 3' cleavage analysis of SV40 early precursor RNAs containing altered downstream sequences. (SV40/ +18 ) The replacement of sequences $3^{\prime}$ to +18 [18 nucleotides downstream of the poly $(A)$ site] by plasmid sequences; $(\mathrm{SV} 40 /+5)$ plasmid sequences replace SV40 sequences downstream of +5 ; $(\mathrm{SV} 40 /+5 / \mathrm{E} 2 \mathrm{~A})$ the Ad5 E2A poly(A) site downstream element at position +5 .

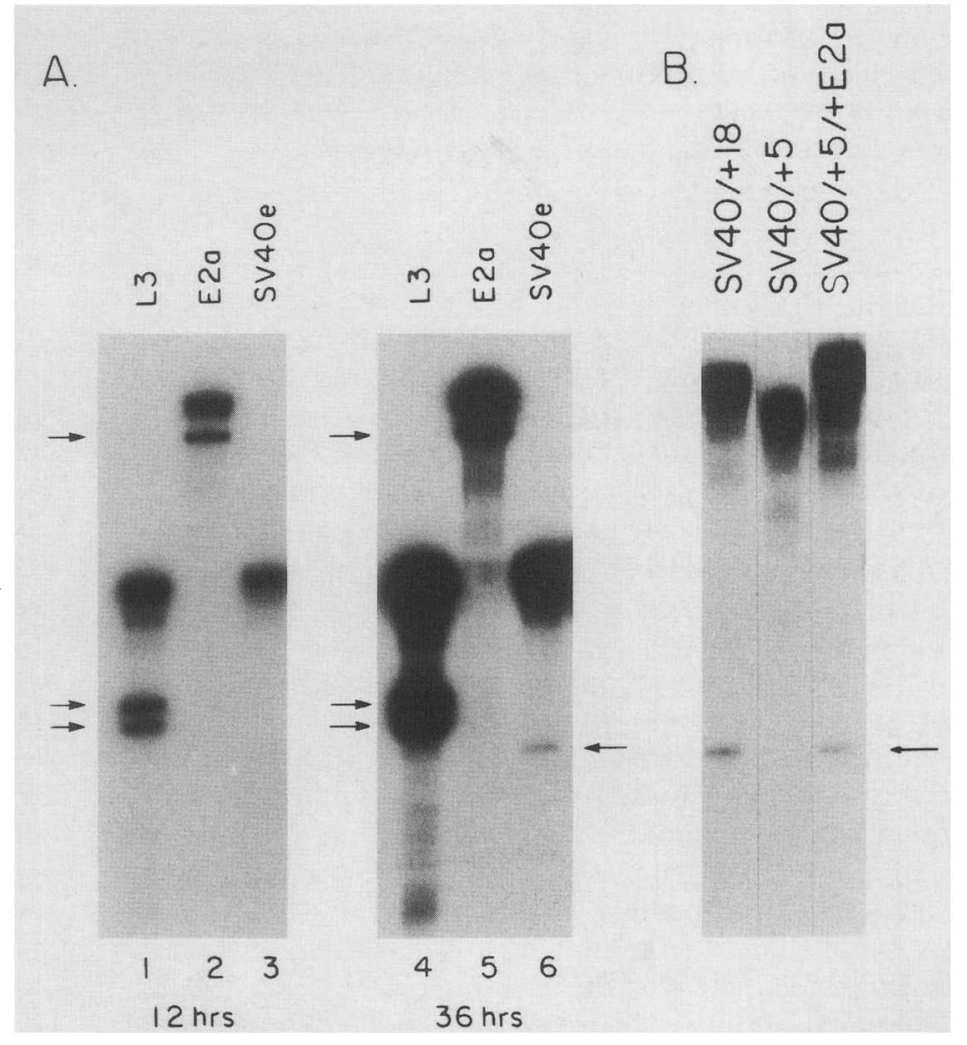




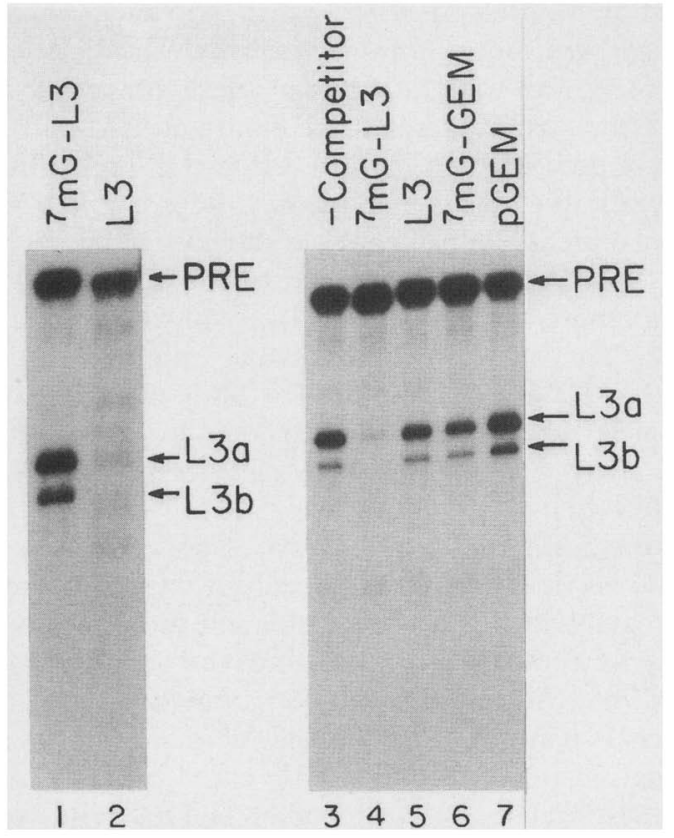

Figure 2. $5^{\prime}$ cap requirement for cleavage at the $\mathrm{L} 3$ poly(A) site. The cleavage reaction was carried out using capped $/ 7 \mathrm{meG}-$ L3) or uncapped (L3) L3 precursor RNA (lanes 1 and 2). Competitions for processing of the L3 precursor (lanes 4-7) were carried out in the presence of a 100-fold molar excess of unlabeled competitor RNA. (pGEM) An SP6 transcript from the plasmid pGEM-2 linearized at the PvuII site. (7me-GEM) capped SP6 pGEM transcript.

ysis of these RNAs in vivo (Hart et al. 1985a; McDevitt et al. 1986) and indicate that the sequence motifs recognized in vivo are also recognized in the nuclear extract. Because the L3 precursor was processed the most efficiently of the pre-mRNAs tested, we chose to utilize this RNA for subsequent fractionation assays.

\section{$A 5^{\prime}$ cap is required for complex formation}

In contrast to the efficient $3^{\prime}$ processing of the capped L3 precursor, incubation of uncapped precursor in the nuclear extract revealed little, if any, cleavage at the poly(A) site (Fig. 2). This does not appear to be simply due to degradation of the uncapped pre-mRNA because the majority of this RNA is still intact after the incubation. These results are in contrast to a recent report indicating that uncapped pre-mRNA was degraded rapidly in nuclear extracts and that in spite of this degradation there was efficient $3^{\prime}$ processing (Ryner and Manley 1987). We can only speculate that differences in extracts or RNA substrates could account for the discrepancy. Because, in our experiments, the uncapped RNA is relatively stable, possesses the proper poly(A) site sequences, yet is inefficiently processed, the results suggest a problem with recognition and/or complex formation. We have shown previously that poly(A) site processing could be inhibited by the addition of the cap analog ${ }^{7} \mathrm{meGpppG}$ to the reaction (Hart et al. 1985b). However, inhibition required a large (5000-fold) molar excess of the cap analog, suggesting an inefficient competition for a cap recognition factor. In contrast, if capped L3 precursor RNA is used as the competitor (100-fold excess), competition is quite efficient, as shown in lane 4 of Figure 2. That such competition involved recognition of the cap is demonstrated by the lack of competition with the identical precursor devoid of a cap (lane 5). Interestingly, a capped RNA lacking a poly(A) site also failed to compete (lane 6), indicating that competition only occurs when the competitor possesses the required RNA sequence motifs, as well as a cap structure. These results indicate that the efficient competition in this experiment is not due to the cap per se but, rather, to the combination of a capped $5^{\prime}$ end and an authentic precursor RNA, suggesting the formation of a processing complex dependent on recognition of the cap. Recognition of the $5^{\prime}$ cap is also consistent with the presence of oligonucleotides containing the capped $5^{\prime}$ end of the RNA in anti-Sm immunoprecipitates of a polyadenylation reaction (Hashimoto and Steitz 1986).

\section{Fractionation of nuclear extracts reveals multiple components}

As an approach to identifying the components responsible for 3 '-end processing, we have subjected a nuclear extract to column chromatography. A HeLa cell nuclear extract was applied to a DEAE-Sephacel column in 0.08 $\mathrm{M} \mathrm{KCl}$ and then eluted in steps with buffer containing $0.25 \mathrm{M}$ and $0.50 \mathrm{M} \mathrm{KCl}$. The three fractions were concentrated by ammonium sulfate precipitation, dialyzed, and assayed for cleavage activity. As seen in Figure 3A, no single fraction was active in cleavage of the $\mathrm{L} 3$ precursor when assayed alone, whereas mixing of the three fractions in equal amounts restored cleavage. Therefore, there appear to be multiple distinct activities required for L3 poly(A) site cleavage that can be reconstituted after the components are separated. Because the results of the initial fractionation indicated the presence of multiple factors, we repeated the DEAE-chromatography in a more extensive fashion. In particular, intermediate cuts prior to the $0.5 \mathrm{M}$ elution step were collected, and various combinations of the individual fractions were assayed to determine the minimal number of components. Assays of the various combinations of the fractions suggested that at least three factors must be involved in the specific cleavage activity (Fig. 3B). Near full activity could be restored by combining the D.15, D.25, and D.60 fractions (lane 13). Partial activity was restored by combining the D.15 and D.35 fractions (lane 7) or by employing the D. 35 fraction in place of the D. 25 fraction (lane 14). We conclude that the principal activities are in the D.15, D.25, and D.60 fractions and that the D.35 fraction contains some of the D.25 and D.60 activities. The appearance of L3a and L3b as doublets in Figure $3 \mathrm{~B}$ is an artifact that can be eliminated by the inclusion of $0.1 \mathrm{mM} \mathrm{MgCl}_{2}$ in the processing reaction (data not shown).

The combined fractions were able to reproducibly reconstitute cleavage activity to a level of $>75 \%$ that of 


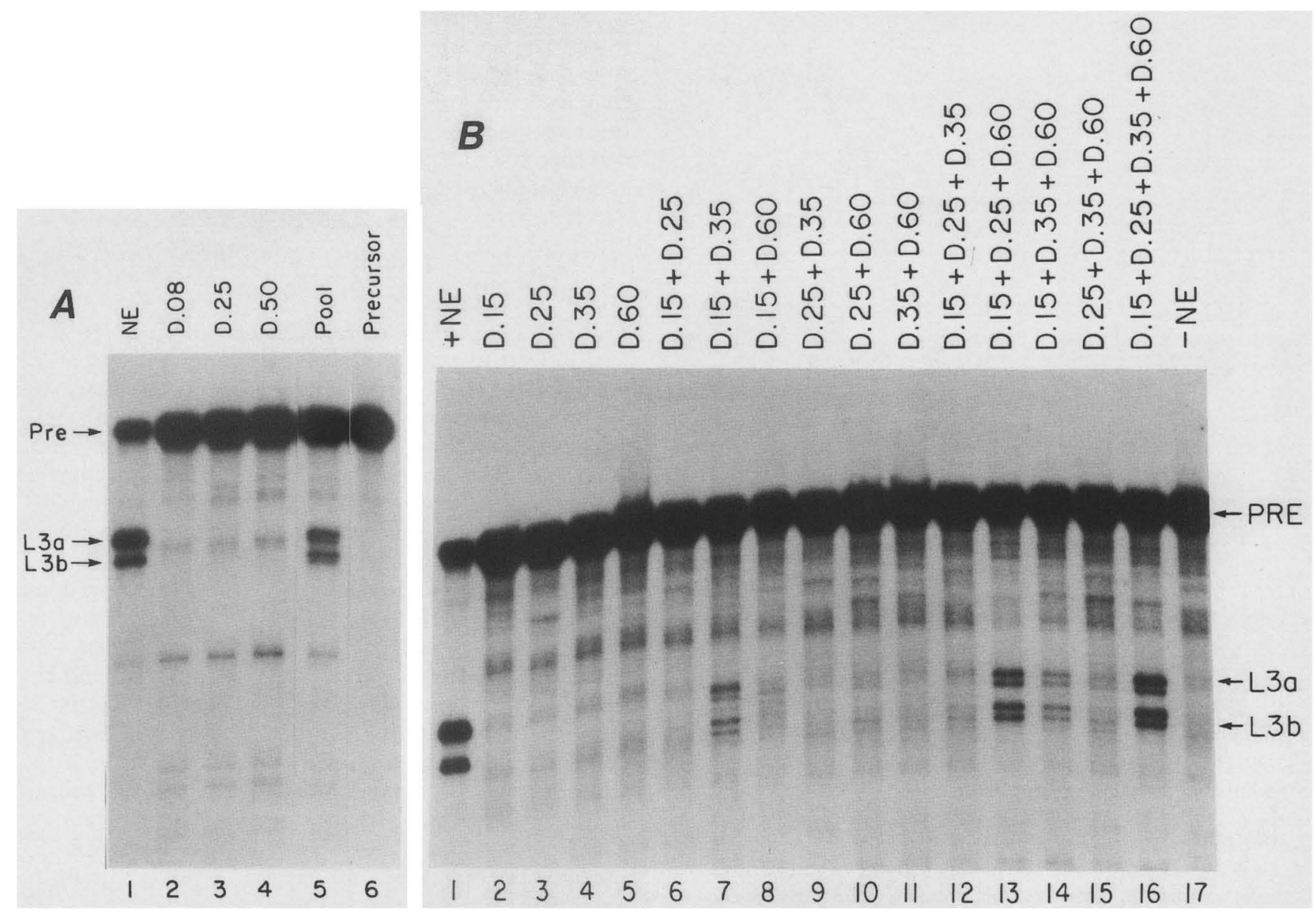

Figure 3. Fractionation of a nuclear extract by DEAE-Sephacel chromatography. (A) A DEAE-Sephacel column was loaded with a nuclear extract in $80 \mathrm{mM} \mathrm{KCl}$, as described in Experimental procedures. The column was step eluted with $250 \mathrm{mM}$ (D.25) and 500 mM (D.50) $\mathrm{KCl}$. Cleavage reactions of the L3 precursor were carried out using each of the individual fractions or a pool containing equal amounts of each fraction. (NE) Nuclear extract. (B) A DEAE-Sephacel column was loaded with a nuclear extract in $150 \mathrm{~mm} \mathrm{KCl}$, as described in Experimental procedures. The column was step eluted with $250 \mathrm{~mm}$ (D.25), $350 \mathrm{~mm}$ (D.350), and 600 mM (D.60) KCl. Cleavage reactions of the L3 precursor were carried out using each of the individual fractions or combinations of equal amounts of each fraction.

the unfractionated nuclear extract, indicating that no critical component was lost. Furthermore, the individual fractions appear to be distinct components, as evidenced by their differential sensitivity to heat inactivation (shown in Fig. 4). The D.15 component was resistant to inactivation at $45^{\circ} \mathrm{C}$, whereas incubation at $55^{\circ} \mathrm{C}$ destroyed its activity. In contrast, the D.25 fraction was sensitive to treatment at $45^{\circ} \mathrm{C}$, as well as at $55^{\circ} \mathrm{C}$, whereas the D.60 fraction appeared to be heat stable because a $55^{\circ} \mathrm{C}$ treatment had no detectable effect on its activity. These results, together with the behavior on DEAE chromatography, strongly suggest that at least three distinct components are necessary for efficient and accurate 3 ' cleavage at the $\mathrm{L} 3$ poly(A) site.

\section{The D.6 fraction relieves non-specific inhibition}

It is now well established that small nuclear ribonucleoprotein particles (snRNPs) play an essential role in RNA processing, including histone $3^{\prime}$-end formation /Galli et al. 1983) and pre-mRNA splicing (for reviews, see Maniatis and Reed 1987; Sharp 1987). Therefore, to begin to characterize the nature of the individual factors required for $3^{\prime}$ processing, we have tested the sensitivity of each fraction to micrococcal nuclease, which has been used previously to investigate the presence of snRNPs (Furneaux et al. 1985; Krainer and Maniatis 1985; Hashimoto and Steitz 1986). Indeed, as shown in Figure 5A, digestion of the nuclear extract with micrococcal nuclease prior to the addition of the L3 precursor abolished the 3 '-processing activity, indicating the presence of at least one essential RNA component.

A previous report has cast some doubt on the interpretation of micrococcal nuclease experiments, as it was found that 3 '-processing activity could be restored to a nuclease-treated extract by simply adding nonspecific RNA (Ryner and Manley 1987). This might suggest the release of RNA-binding proteins during the micrococcal nuclease digestion, which then inhibit cleavage nonspecifically by binding to the precursor RNA. To test such a 


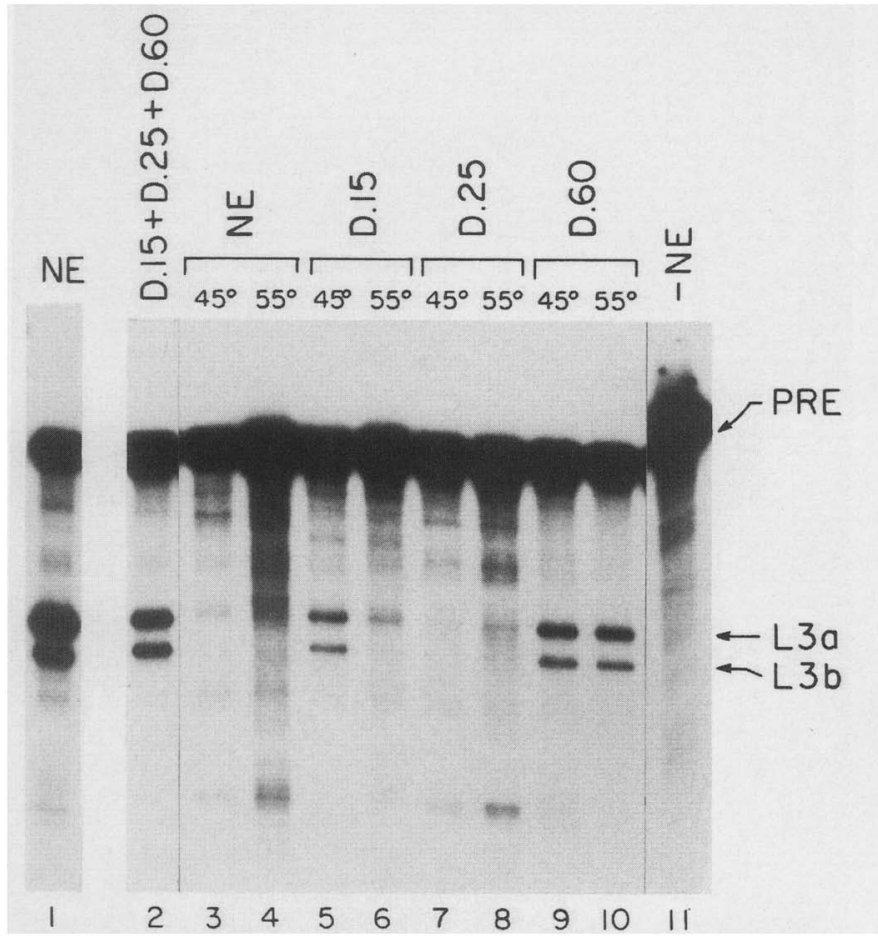

Figure 4. Heat sensitivity of the $3^{\prime}$ cleavage activities. DEAE fractions were obtained as described in Experimental procedures. (Lanes 3-10) Nuclear extract or individual DEAE fractions were treated at the indicated temperature for $10 \mathrm{~min}$, combined with the two other untreated fractions, and tested for L3 cleavage activity. (Lane 1) The nuclear extract (NE) assayed before fractionation; (lane 2) an untreated control reaction containing equal amounts of the three DEAE fractions required for cleavage activity; (lane 11) the unreacted precursor RNA.

possibility, the micrococcal assays were performed with and without the addition of various nonspecific RNAs. In addition, we titrated the amount of micrococcal nuclease necessary to give full inhibition. As shown in Figure 5A, the addition of yeast RNA to an extract treated with micrococcal nuclease $(90 \mathrm{U} / \mathrm{ml})$ restored activity. However, if the micrococcal nuclease was increased to 360 units $/ \mathrm{ml}$, there was little effect upon the addition of yeast RNA. These results thus suggested the possibility that in addition to a nonspecific effect, nuclease digestion also resulted in the loss of a specific component.

To determine whether one of the fractions possessed an RNA component critical for activity, the individual DEAE fractions were treated separately with micrococcal nuclease and then combined with untreated fractions to assay for 3 ' cleavage. As shown in Figure 5B, the D.15 fraction was insensitive to micrococcal nuclease digestion. In contrast, the activity of the D.25, as well as the D.60, fraction was sensitive to micrococcal nuclease digestion. To test for specificity, Escherichia coli rRNA was added to each of these nuclease-treated fractions. As shown in Figure 6A, there was efficient restoration of cleavage activity to the nuclease-treated D.60 fraction by the addition of rRNA. Furthermore, the D. 60 fraction could be completely replaced by either $60 \mu \mathrm{g} / \mathrm{ml}$ of rRNA or $80 \mu \mathrm{g} / \mathrm{ml}$ of heparin (Fig. $6 \mathrm{~B}$ ). We therefore conclude that the D.6 fraction, which contains $90 \%$ of the RNA present in the nuclear extract (data not shown), serves to sequester inhibitory factors present in the extract, because this fraction can even be replaced by the nonphysiological polyanion heparin.

\section{The D.25 fraction contains an essential RNA component and an Sm determinant}

Because the data of Figure 5 suggested the possibility of a specific requirement for RNA in cleavage and the D. 25 fraction was also sensitive to micrococcal nuclease, we investigated the properties of the D.25 fraction further. As shown in Figure 7A, in contrast to the results with the D.6 fraction, activity could not be restored to the micrococcal nuclease-treated D.25 fraction by the addition of RNA. Furthermore, simply replacing the D.25 fraction with rRNA yielded no activity (data not shown). From these data we conclude that the D.25 fraction contains an RNA component essential for the activity of this fraction.

Previous experiments have demonstrated an inhibition of poly(A) site processing by anti-Sm antisera (Moore and Sharp 1985; Sperry and Berget 1986). Our experiments demonstrate that this $\mathrm{Sm}$ component is required for the $3^{\prime}$-cleavage reaction but not the subsequent poly(A) addition (McDevitt et al. this issue). As we suspected that the D.25 fraction contained an snRNP, based on the finding that this fraction possesses an RNA component essential for activity, we tested the D.25 fraction for sensitivity to Sm-specific antisera. In particular, we assayed the D.25 fraction in the reconstituted 3 '-cleavage assay after depletion with a $\mathrm{Sm}$ monoclonal antibody bound to protein A-Sepharose. As described by Kramer et al. (1984), such an approach is effective in testing whether a particular antigenic component is required for the reconstituted reaction. As shown in Figure $7 \mathrm{~B}$, treatment of the D.25 fraction with the Y12 $\alpha-\mathrm{Sm}$ monoclonal antibody bound to protein A-Sepharose reduced cleavage activity 10 -fold when compared to treatment with a control antibody bound to protein A-Sepharose. Thus, the D.25 fraction appears to possess an Sm determinant involved in the $3^{\prime}$-cleavage process; given the fact that this fraction also possesses an RNA component essential for activity, we conclude that the D.25 activity is probably an snRNP.

\section{Discussion}

By all accounts, the processing of various poly $(\mathrm{A})$ sitecontaining synthetic RNAs in HeLa cell nuclear extracts is an authentic representation of the in vivo reaction. Specific cleavage has been demonstrated for three RNAs containing distinct poly(A) sites. Furthermore, there is a requirement for each of the RNA sequence motifs that have been demonstrated to be required in vivo, as well as for a $5^{\prime}$ cap structure. The role of the cap in RNA processing has been somewhat of a controversial issue. In 


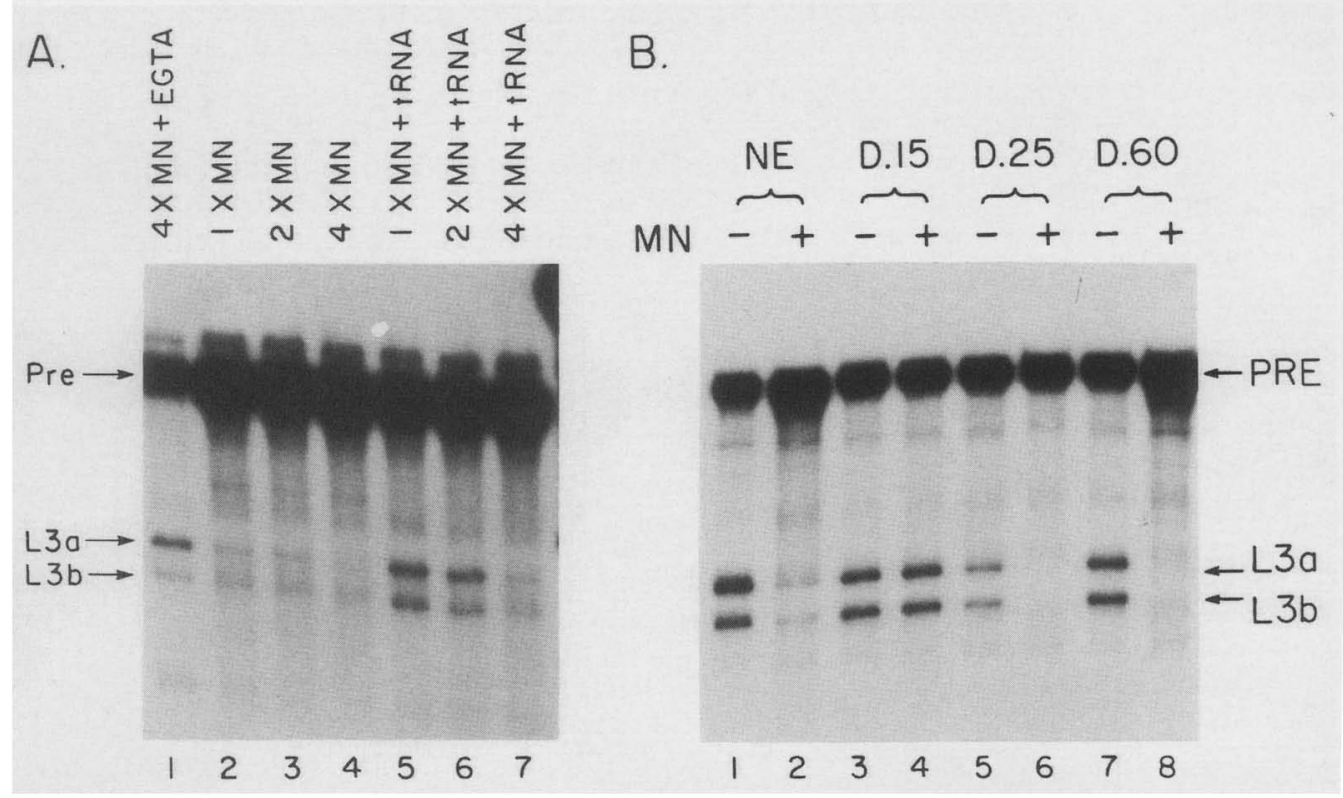

Figure 5. Micrococcal nuclease (MN) sensitivity of the L3 $3^{\prime}$-cleavage factors. $(A)$ Titration of the amount of micrococcal nuclease required to completely inhibit $3^{\prime}$ cleavage of the $\mathrm{L} 3$ precursor in a nuclear extract. $1 \times \mathrm{MN}$ represents 90 units of micrococcal nuclease per milliliter of sample. $(4 \times \mathrm{MN}+$ EGTA) EGTA was added prior to the addition of $360 \mathrm{U} / \mathrm{ml}$ micrococcal nuclease. In the other samples, EGTA was added after nuclease treatment and before the addition of substrate. (Lanes 5-7) Yeast RNA (1.5 $\mu$ g) was added to each reaction after nuclease treatment and the addition of EGTA. $(B)$ Micrococcal nuclease sensitivity of the individual DEAE fractions required for L3 3 ' cleavage. DEAE fractions were treated with nuclease and combined with the other two untreated fractions required for cleavage activity. (- | EGTA was added prior to micrococcal nuclease treatment. $|+|$ EGTA was added following nuclease treatment.

vitro pre-mRNA splicing is much more efficient with capped precursors, although the stringency appears to depend on the nature of the extract (Konarska et al. 1984; Krainer et al. 1984; Edery and Sonenberg 1985). In addition, preincubation of the extract with cap analogs can inhibit in vitro splicing effectively (Konarska et al. 1984; Edery and Sonenberg 1985; Patzelt et al. 1987), as well as spliceosome formation (Patzelt et al. 1987). The presence of a cap has also been shown to be required for the 3' processing of histone pre-mRNA in vivo /Georgiev et al. 1984). Furthermore, these results are consistent with the presence of cap-containing oligonucleotides in anti-Sm precipitates of in vitro $3^{\prime}$ processing reactions (Hashimoto and Steitz 1986; Mowry and Steitz 1987a). Our data suggest a role for the cap in facilitating the formation of a polyadenylation complex in concert with the required RNA sequence motifs that flank the poly(A) site.

The results presented in this paper have allowed a characterization of the factors responsible for the 3 '-endonucleolytic cleavage event and have demonstrated a complexity in the process reflected in the requirement for multiple factors. We conclude that there are at least two distinct components necessary for correct and efficient 3 -end cleavage based on the fractionation studies, the heat sensitivity assays, and the sensitivity of the components to micrococcal nuclease digestion. Whether there are additional factors involved is difficult to say at this time, although preliminary results from further fractionation have not yielded any evidence for additional factors. One of the factors appears to contain an essential RNA component, as suggested by its sensitivity to micrococcal nuclease. Based on these assays, as well as the inhibition with anti-Sm antisera, we conclude that the D.25 factor necessary for the $3^{\prime}$ cleavage reaction is most likely an snRNP. The requirement for an array of snRNPs in the splicing reaction has been well established (for review, see Maniatis and Reed 1987; Sharp 1987), and there is also clear evidence for the involvement of an snRNP in the $3^{\prime}$ processing of histone pre-mRNA (Galli et al. 1983; Gick et al. 1986; Strub and Birnstiel 1986; Mowry and Steitz 1987a,b; Cotten et al. 1988). What might be the role played by an snRNP in the process of 3 '-end formation? snRNPs involved in other RNA processing reactions, in particular the U7 /Shaufele et al. 1986) and U1 (Zhuang and Weiner 1986) snRNPs, mediate the recognition of specific pre-mRNA sequences by RNA : RNA base pairing. It seems likely that the essential RNA component of the D. 25 fraction is responsible for the recognition of one of the genetic elements in the pre-mRNA required for efficient $3^{\prime}$-end cleavage. Two recognition signals for the 3 '-end processing of a pre-mRNA have been defined, and these may be the only required signals. First, there is the highly conserved AAUAAA element that precedes the cleavage site by 10-30 nucleotides (Proudfoot and Brownlee 1976). Single-base substitutions have shown unambiguously that this element is required for the cleavage reaction (Fitzgerald and Shenk 1981; Montell et al. 1983; Wickens and Stephenson 1984). In support of recognition of the AAUAAA by an snRNP are the results of Hashimoto and Steitz (1986), which demon- 


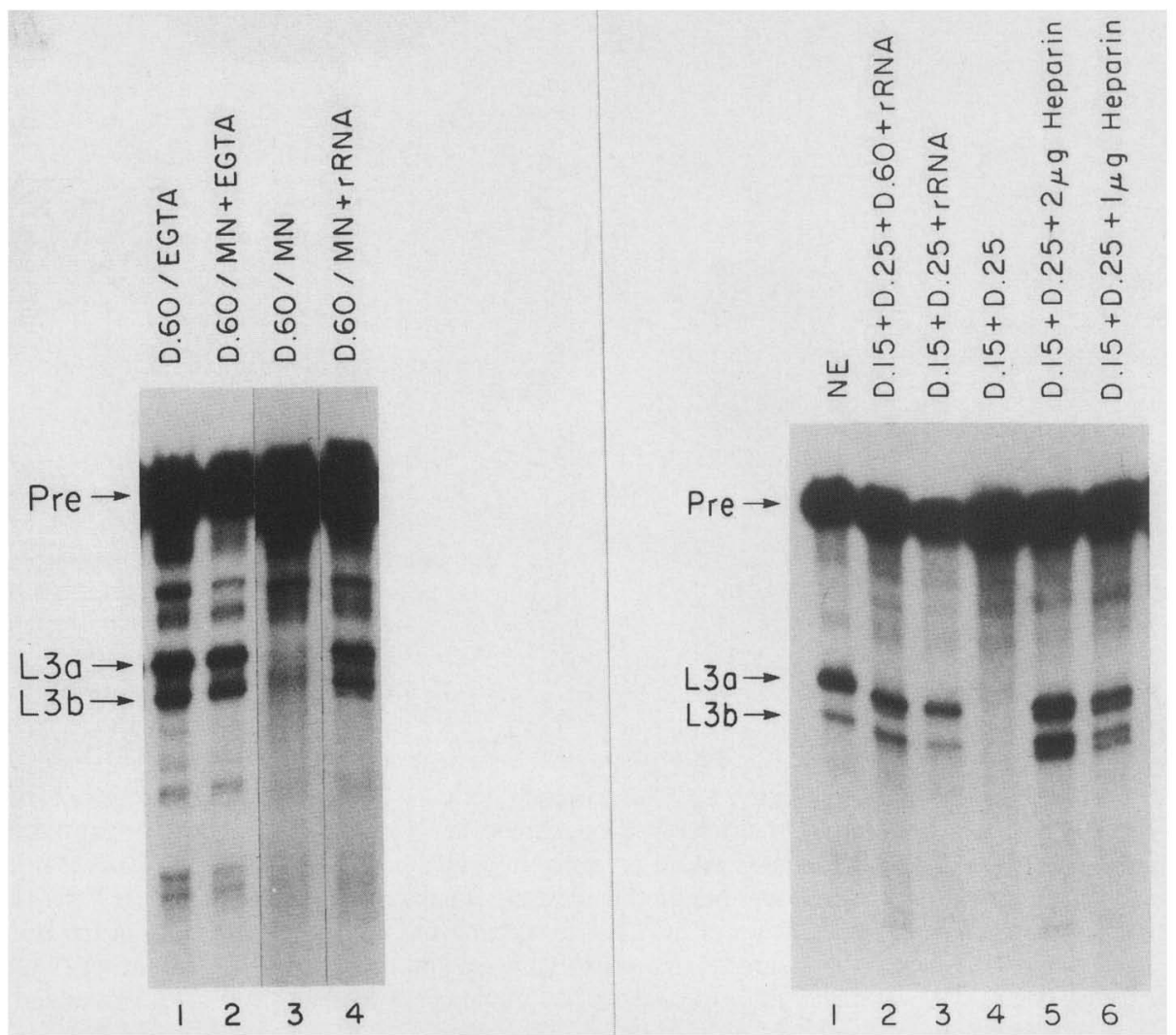

Figure 6. Micrococcal nuclease (MN) sensitivity of cleavage factors. (A) Complementation of micrococcal nuclease-treated D.60 fraction with E. coli rRNA. (Lane 1) The D.60 fraction was treated with 2 mM EGTA and combined with untreated D.15 and D.25 fractions; (lane 2) the D.60 fraction was treated with micrococcal nuclease $(360 \mathrm{U} / \mathrm{ml})$ in the presence of EGTA; (lane 3) the D.60 fraction was treated with micrococcal nuclease $(360 \mathrm{U} / \mathrm{ml})$ and EGTA was then added; (lane 4) as in lane 3 but with the addition of 1.5 $\mu \mathrm{g}$ of rRNA after nuclease treatment. (B) Replacement of the D.60 fraction by rRNA or heparin in the L3 3 '-cleavage reaction. DEAE fractions were obtained as described in Experimental procedures. (Lane 1) A control reaction with nuclear extract; (lane 4) a reaction with only D.15 and D.25; (lanes 5 and 6) as in lane 4 but including $2 \mu \mathrm{g}$ (lane 5) or $1 \mu \mathrm{g}$ heparin in the reaction. The cleavage reactions in lanes 2 and 3 contained $1.5 \mu \mathrm{g}$ of E. coli rRNA, in addition to D.15 and D.25 fractions. The reaction in lane 2 also has D.60.

strated a physical association between an Sm-containing component and pre-mRNA sequences containing the AAUAAA. However, if an snRNP does recognize the AAUAAA, it is somewhat puzzling that it is not involved in the in vitro poly(A) addition reaction that also requires the AAUAAA element in the pre-mRNA (Manley et al. 1985; Zarkower et al. 1986; McDevitt et al., this issue). However, as demonstrated in McDevitt et al. (this issue), there is no evidence from micrococcal nuclease studies for an RNA in the poly(A) addition reaction, and the process is insensitive to the addition of an anti-Sm monoclonal antibody. Thus, the D.25 factor described in this paper, which contains an essential RNA component and is sensitive to an anti-Sm antibody, is unlikely to be involved in both cleavage and poly $(\mathrm{A})$ addition.

In addition to the AAUAAA element, there is also a less well-conserved sequence element downstream of the cleavage site in the pre-mRNA that is required for efficient processing (McDevitt et al. 1984). Therefore, this genetic element, which is required only for the $3^{\prime}$ cleavage of the pre-mRNA and not the subsequent polyadenylation (Moore et al., 1986; Zarkower et al. 1986), may be a target for interaction with the RNA-containing component in the D.25 fraction. Interestingly, the U7 snRNP recognizes a conserved RNA sequence necessary for histone 3 '-end processing, and this sequence is downstream of the site of cleavage (Schaufele et al. 1986; Mowry and Steitz 1987a,b). Of course, such a scenario is at odds with the immunoprecipitation results of Hashimoto and Steitz (1986). However, we might speculate that perhaps there is a primary recognition of a downstream sequence, which then facilitates stable interaction at the AAUAAA.

Although the majority of downstream elements that have been defined through mutagenesis exhibit a GUrich or U-rich motif, there is no strict sequence conservation (Birnstiel et al. 1985; Hart et al. 1985b; McDevitt et al. 1986; Gil and Proudfoot 1986). This has led to the speculation that interactions involving the downstream sequence might dictate the efficiency of the poly(A) site usage (McDevitt et al. 1984, 1986). This could involve a single recognition factor capable of recognizing a large array of specific RNA sequences with varying affinity. Alternatively, there may be multiple factors that recognize different downstream sequences in a fashion not 


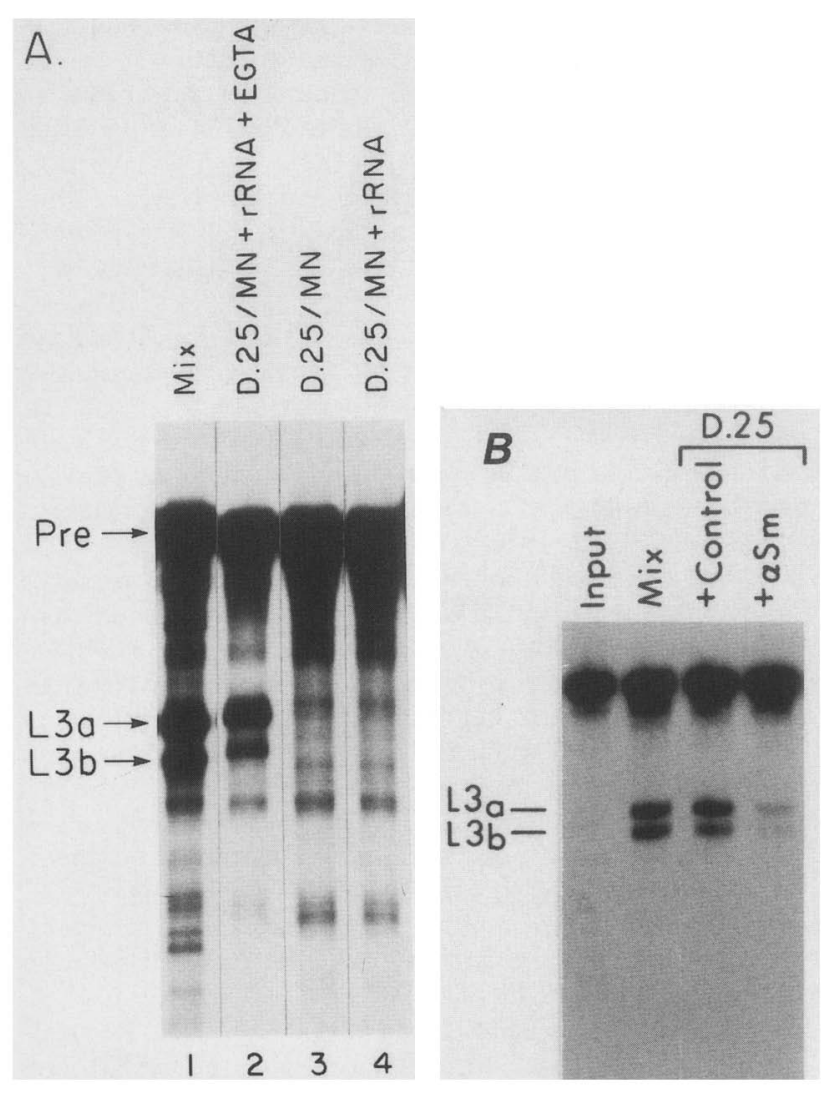

Figure 7. The D. 25 fraction contains an essential RNA and is inhibited by $\mathrm{Sm}$ monoclonal antibody. $(A)$ Lack of complementation of micrococcal nuclease (MN)-treated D.25 fraction with E. coli rRNA. (Lane 1) Untreated D.15, D.25, and D.60, combined in equal amounts; (lane 2) the D.25 fraction was treated with micrococcal nuclease $(90 \mathrm{U} / \mathrm{ml})$ in the presence of EGTA, and $1.5 \mu \mathrm{g}$ of rRNA was added to the cleavage reactions; (lane 3) the D.25 fraction was nuclease treated $(90$ $\mathrm{U} / \mathrm{ml}$ ) and EGTA was then added (lane 4 ) as in lane 3 but with the addition of $1.5 \mu \mathrm{g}$ of rRNA after nuclease treatment; $(B)$ The D.25 fraction was depleted with either a control antibody coupled to protein A-Sepharose or the Y12 monoclonal $(\alpha-\mathrm{Sm})$ coupled to protein A-Sepharose, as described in Experimental procedures. The supernatant remaining after spinning out the resin was mixed with the other untreated fraction and assayed for 3 '-cleavage activity using the $\mathrm{L} 3$ precursor. (Lane mix) A control reaction without antibody treatment.

unlike the interaction of various transcription factors with specific promoter sequences. The resolution of this issue is of some significance because the efficiency of poly(A) site usage can be a regulated event, and the downstream element would appear to be the best candidate as the target for this regulation.

Finally, several other questions remain, including the nature of the endonuclease that actually carries out the cleavage reaction. Certainly, the D.15 fraction could provide this role. The ability to assay for and isolate the factors involved in the process of poly(A) site formation affords the possibility of investigating the basis for the control of $3^{\prime}$-mRNA processing.

\section{Experimental procedures}

Cells and extracts

HeLa cells were grown in suspension in Joklik's modified minimal essential medium (MEM), containing $5 \%$ calf serum. The nuclear extracts were prepared essentially as described by Dignam et al. (1983), except the nuclei were extracted with 350 $\mathrm{mM} \mathrm{KCl}$ and all buffers contained $0.1 \mathrm{~mm}$ phenylmethylsulfonyl fluoride (PMSF).

\section{Preparation of ${ }^{32}$ P-labeled pre-mRNA}

SP6 RNA synthesis was performed as described previously (Hart et al. 1985b) in the presence of $0.5 \mathrm{mM}^{7} \mathrm{meG}\left(5^{\prime}\right) \mathrm{ppp}\left(5^{\prime}\right) \mathrm{G}$ (Pharmacia), $12 \mu \mathrm{M}$ UTP, and $0.4 \mu \mathrm{M}$ [ $\left.{ }^{32} \mathrm{P}\right] \mathrm{UTP}$. Plasmid $\Delta 6 \mathrm{C}$, containing the E2A poly(A) site (Hart et al. 1985a), was cut with BamHI before transcription. Plasmid $\Delta 7 \mathrm{C}$ is identical to $\mathrm{p} \Delta 6 \mathrm{C}$, except the inserted adenovirus sequences are in the opposite orientation relative to the $\mathrm{Sp} 6$ promoter, allowing synthesis of L3 pre-mRNA sequence, and there are 15 fewer nucleotides of adenovirus sequence upstream of the L3 poly(A) site. The SV40 early templates have been described by Hart et al. (1985b) and McDevitt et al. (1986). RNA transcripts were gel purified prior to incubation in the processing reaction and stored in $30 \%$ ethanol.

\section{Assay for 3' processing}

The standard processing reactions were carried out in a total volume of $25 \mu \mathrm{l}$ containing $60 \%$ nuclear extract [in $100 \mathrm{mM}$ $\mathrm{KCl}, 20 \mathrm{~mm}$ HEPES (pH 7.9), 10\% glycerol, 0.2 mM EDTA, 0.1 mM PMSF, and $0.5 \mathrm{mM}$ dithiothreitol (DTT)], 2\% polyvinyl alcohol, 0.5 mM 3' dATP (Pharmacia), and 0.5-2 nM pre-mRNA. Later experiments using DEAE fractions incorporated 0.1 or 0.5 $\mathrm{mM} \mathrm{MgCl}_{2}$ in the reaction buffer. Reactions were incubated for 90-180 $\mathrm{min}$ at $30^{\circ} \mathrm{C}$ and were subsequently treated as before (Hart et al. 1985b).

\section{Column chromatography}

A DEAE-Sephacel (Pharmacia) column $(9.5 \times 0.7 \mathrm{~cm})$ was equilibrated in buffer A [ $20 \mathrm{~mm}$ HEPES $(\mathrm{pH} 7.9), 10 \%$ glycerol, $0.2 \mathrm{~mm}$ EDTA, $0.1 \mathrm{~mm}$ PMSF, $0.5 \mathrm{~mm} \mathrm{DTT}$ ] and $\mathrm{KCl}$, as specified in the text. Nuclear extract (usually $4 \mathrm{ml}, \sim 5 \mathrm{mg} / \mathrm{ml}$, corresponding to $7 \times 10^{8}$ cell equivalents) was loaded at $10 \mathrm{ml} / \mathrm{hr}$. The column was washed and eluted, as specified in the text. Protein-containing fractions were precipitated by the addition of ammonium sulfate to $65 \%$. The precipitated material was resuspended in buffer A containing $100 \mathrm{mM} \mathrm{KCl}$, dialyzed, and stored at $-70^{\circ} \mathrm{C}$.

\section{Micrococcal nuclease treatment}

Nuclease treatment was carried out in the presence of $1 \mathrm{~mm}$ $\mathrm{CaCl}_{2}$ at $30^{\circ} \mathrm{C}$ for $30 \mathrm{~min}$, with the addition of 90 to 360 units of micrococcal nuclease (Pharmacia) per milliliter of extract. The nuclease was inactivated by the addition of EGTA to a final concentration of $2 \mathrm{~mm}$. The negative control in each case involved the addition of $2 \mathrm{mM}$ EGTA prior to the addition of nuclease and subsequent incubation at $30^{\circ} \mathrm{C}$ for $30 \mathrm{~min}$.

\section{Immunodepletion}

The immunodepletion was performed exactly as described in Kramer et al. (1984), except that $50 \mu l$ of packed, protein ASepharose (Pharmacia) was used with $50 \mu$ l of the various sera. 
After the initial depletion, the procedure was repeated with fresh antibody-protein A-Sepharose. After spinning out the resin, the supernatant was assayed.

\section{Antisera}

A mouse ascites fluid, prepared as described by Lerner et al. (1981), was the source of the Y-12 monoclonal antisera. The control sera M162 was also from a mouse ascites and is specific for a DNA-binding protein in Epstein-Barr virus (EBV)-infected cells (W. Reeves).

\section{Acknowledgments}

We thank Kim Mowry, Mei-di-Shu, and Joan Steitz for generously providing Y12 antisera, cells, and much helpful advice. We also thank Suzanne Scarola for her excellent assistance in the preparation of nuclear extracts and Lynn Vales for providing a HeLa RNA sample from adenovirus-infected cells. M.A.M. is a National Institutes of Health (NIH) Medical Scientist Training Program Fellow. This work was supported by a grant from the NIH (GM35894).

\section{References}

Alt, F.W., A.L.M. Bothwell, M. Knapp, E. Siden, E. Mather, M., Koshland, D. Baltimore. 1980. Synthesis of secreted and membrane-bound immunoglobulin $\mu$-heavy chains is directed by mRNAs that differ at their $3^{\prime}$ ends. Cell 20: $293-$ 302.

Birnstiel, M.L., M. Busslinger, and K. Strub. 1985. Transcription termination and $3^{\prime}$ processing: The end is in site! Cell 41: $349-359$.

Blattner, F.R. and P.W. Tucker. 1984. The molecular biology of immunoglobulin D. Nature 307: 417-442.

Cotten, M., O. Gick, A. Vasserot, G. Schaffner, and M.L. Birnsteil. 1988. Specific contacts between mammalian U7 snRNA and histone precursor RNA are indispensable for the in vitro 3' RNA processing reaction. EMBO 1. 7: 801-808.

Dignam, J.D., R.M. Lebovitz, and R.G. Roeder. 1983. Accurate transcription initiation by RNA polymerase II in a soluble extract from isolated mammalian nuclei. Nucleic Acids Res. 11: $1475-1489$.

Early, P., J. Rogers, M. Davis, K. Calame, M. Bond, R. Wall, and L. Hood. 1979. Two mRNAs can be produced from a single immunoglobulin $\mu$ gene by alternative RNA processing pathways. Cell 20: 313-319.

Early, P., J. Rogers, M. Davis, K. Calame, M. Bond, R. Wall, and L. Hood. 1980. Two mRNAs can be produced from a single immunoglobulin gene by alternative RNA processing pathways. Cell 20: 313-319.

Edery, I. and N. Sonenberg. 1985. Cap-dependent RNA splicing in a HeLa nuclear extract. Proc. Natl. Acad. Sci. 82: 75907594.

Fitzgerald, M. and T. Shenk. 1981. The sequence 5'-AAUAAA$3^{\prime}$ forms part of the recognition site for polyadenylation of late SV40 mRNAs. Cell 24: 251-260.

Furneaux, H.M., K.K. Perkins, G.A. Freyer, J. Arenas, and J. Hurwitz. 1985. Isolation and characterization of two functions from HeLa cells required for mRNA splicing in vitro. Proc. Natl. Acad. Sci. 82: 4351-4355.

Galli, G., H. Hofstetter, H.G. Stunnenberg, and M.L. Birnstiel. 1983. Biochemical complementation with RNA in the Xenopus oocyte: A small RNA is required for the generation of $3^{\prime}$ histone mRNA termini. Cell 34: 823-828.
Galli, G., J.W. Guise, M.A. McDevitt, P.W. Tucker, and J.R. Nevins. 1987. Relative position and strengths of poly(A) sites as well as transcription termination are critical to membrane versus secreted $\mu$-chain expression during B-cell development. Genes Dev. 1: 471-481.

Galli, G., J.W. Guise, P.W. Tucker, and J.R. Nevins. 1988. Poly(A) site choice rather than splice site choice govern the regulated production of IgM heavy chain RNAs. Proc. Natl. Acad. Sci. 85: (in press).

Georgiev, O., J. Mous, and M.L. Brinsteil. 1984. Processing and nucleo-cytoplasmic transport of histone gene transcripts. Nucleic Acids Res. 12: 8539-8551.

Gick, O., A. Kramer, W. Keller, and M.L. Birnstiel. 1986. Generation of histone mRNA 3 ' ends by endonucleolytic cleavage of the pre-mRNA in a snRNP-dependent in vitro reaction. $E M B O$ I. 5: 1319-1326.

Gil, A. and N.J. Proudfoot. 1986. Position-dependent sequence elements downstream of AAUAAA are required for efficient rabbit $\beta$-globin mRNA 3' end formation. Cell 49: 399-406.

Hart, R.P., M.A. McDevitt, H. Ali, and J.R. Nevins. 1985b. Definition of essential sequences and functional equivalence of elements downstream of the adenovirus E2A and the early SV40 poly(A) sites. Mol. Cell. Biol. 5: 2975-2983.

Hart, R.P., M.A. McDevitt, and J.R. Nevins. 1985a. Poly(A) site cleavage in a HeLa nuclear extract is dependent on downstream sequences. Cell 43: 677-683.

Hashimoto, C. and J.A. Steitz. 1986. A small nuclear ribonucleoprotein associates with the AAUAAA polyadenylation signal in vitro. Cell 45: 581-591.

Konarska, M.M., R.A. Padgett, and P.A. Sharp. 1984. Recognition of cap structure in splicing in vitro or mRNA precursors. Cell 38: 731-736.

Krainer, A.R. and T. Maniatis. 1985. Multiple factors including the small nuclear ribonucleoproteins $U 1$ and $U 2$ are necessary for pre-mRNA splicing in vitro. Cell 42: 725-736.

Krainer, A.R., T. Maniatis, B. Ruskin, and M.R. Green. 1984. Normal + mutant human $\beta$-globin pre-mRNAs are faithfully and efficiently spliced in vitro. Cell 36: 993-1005.

Kramer, A.R., W. Keller, B. Appel, and R. Luhrmann. 1984. The 5 ' terminus of the RNA moiety of U1 small nuclear ribonucleoprotein particles is required for the splicing of messenger RNA precursors. Cell 38: 299-307.

Leff, S.E., M.H. Rosenfeld, and R.M. Evans. 1986. Complex transcriptional units: Diversity in gene expression by alternative RNA processing. Annu. Rev. Biochem. 55: 10911117.

Lerner, E.A., M.R. Lerner, C.A. Janeway, Jr., and J.A. Steitz. 1981. Monoclonal antibodies to nucleic acid-containing cellular constituents: Probes for molecular biology and autoimmune disease. Proc. Natl. Acad. Sci. 78: 2737-2741.

Maniatis, T. and R. Reed. 1987. The role of small nuclear ribonucleoprotein particles in pre-mRNA splicing. Nature 325: 673-678.

Manley, J.L., H. Yu, and L. Ryner. 1985. RNA sequence containing hexanucleotide AAUAAA directs efficient mRNA polyadenylation in vitro. Mol. Cell. Biol. 5: 373-379.

McDevitt, M.A., M.J. Imperiale, H. Ali, and J.R. Nevins. 1984. Requirement of a downstream sequence for generation of a poly(A) addition site. Cell 37: 993-999.

McDevitt, M.A., R.P. Hart, W.W. Wong, and J.R. Nevins. 1986. Sequences capable of restoring poly(A) site function define two distinct downstream elements. EMBO J. 5: 2907-2913.

Montell, C., E.F. Fisher, M.H. Caruthers, and A.J. Berk. 1983. Inhibition of RNA cleavage but not polyadenylation by a point mutation in mRNA $3^{\prime}$ consensus sequence AAUAAA. Nature 305: 600-629. 
Moore, C.L. and P.A. Sharp. 1985. Accurate cleavage and polyadenylation of exogenous RNA substrate. Cell 41: 845-855.

Moore, C.L., H. Skolnik-David, and P.A. Sharp. 1986. Analysis of RNA cleavage at the adenovirus-2 L3 polyadenylation site. $E M B O$ I. 5: 1929-1938.

Mowry, K.L. and J.A. Steitz. 1987a. Both conserved signals on mammalian histone pre-mRNAs associate with small nuclear ribonucleoproteins during $3^{\prime}$ end formation in vitro. Mol. Cell. Biol. 7: 1663-1672.

1987b. Identification of the human U7 snRNP as one of several factors involved in the $3^{\prime}$ end maturation of histone premessenger RNAs. Science 238: 1682-1687.

Nevins, J.R. 1983. The pathway of eukaryotic mRNA formation. Annu. Rev. Biochem. 52: 441-466.

- 1984. The role of poly(A) in mRNA biogenesis. In Processing of RNA (ed. D. Apirion), CRC Press, Boca Raton, Florida.

Patzelt, E., E. Thalmann, K.Martinuth, D. Blaas, and E. Kuechler. 1987. Assembly of pre-mRNA splicing complex is cap dependent. Nucleic Acids Res. 15: 1387-1399.

Proudfoot, N.J. and G.G. Brownlee. 1976. 3' non-coding region sequences in eukaryotic messenger RNA. Nature 263: 211214.

Rogers, J., P. Early, C. Carter, K. Calame, M. Bond, L. Hood, and R. Wall. 1980. Two mRNAs with different $3^{\prime}$ ends encode membrane-bound and secreted forms of immunoglobulin $\mu$ chain. Cell 20: 303-312.

Ryner, L.C. and J.L. Manley. 1987. Requirements for accurate and efficient mRNA 3 ' end cleavage and polyadenylation of a simian virus 40 early pre-RNA in vitro. Mol. Cell. Biol. 7: 495-503.

Schaufele, F., G.M. Gilmartin, W. Bannwarth, and M.L. Birnstiel. 1986. Compensatory mutations suggest that basepairing with a small nuclear RNA is required to form the $3^{\prime}$ end of $\mathrm{H} 3$ messenger RNA. Nature 323: 777-781.

Sharp, P.A. 1987. Splicing of messenger RNA precursors. Science 235: 766-771.

Sperry, A.O. and S.M. Berget. 1986. In vitro cleavage of the simian virus 40 early polyadenylation site adjacent to a required downstream TG sequence. Mol. Cell. Biol. 6: 47344741.

Strub, K. and M.L. Birnstiel. 1986. Genetic complementation in the Xenopus oocyte: Co-expression of sea urchin histone and U7 RNAs restores $3^{\prime}$ processing of $\mathrm{H} 3$ pre-mRNA in the oocyte. $E M B O$ J. 5: 1675-1682.

Strub, K., G. Galli, M. Busslinger, and M.L. Birnstiel. 1984. The cDNA sequences of the sea urchin U7 small nuclear RNA suggest specific contacts between histone mRNA precursor and U7 RNA during RNA processing. $E M B O$ J. 3: 28012807.

Wickens, M. and P. Stephenson. 1984. Role of the conserved AAUAAA sequence: Four AAUAAA point mutants prevent messenger RNA 3' end formation. Science 225: 1045-1051.

Zarkower, D., R. Stephenson, M. Sheets, and M. Wickens. 1986. The AAUAAA sequence is required both for cleavage and for polyadenylation of simian virus 40 pre-mRNA in vitro. Mol. Cell. Biol. 6: 2317-2323.

Zhuang, Y. and A.M. Weiner. 1986. A compensatory base change in U1 snRNA suppresses a $5^{\prime}$ splice site mutation. Cell 46: 827-835. 


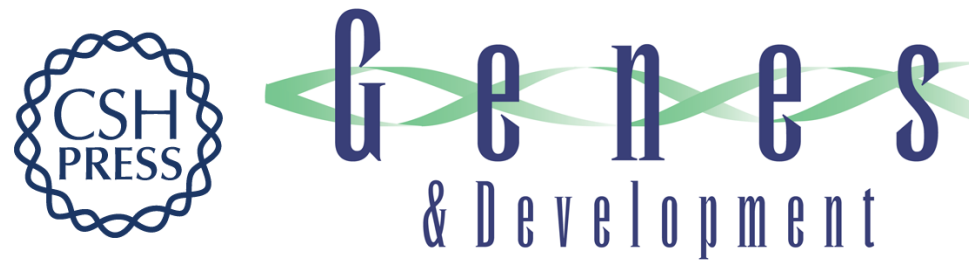

\section{Multiple factors are required for specific RNA cleavage at a poly(A) addition site.}

G M Gilmartin, M A McDevitt and J R Nevins

Genes Dev. 1988, 2:

Access the most recent version at doi:10.1101/gad.2.5.578

References This article cites 46 articles, 12 of which can be accessed free at:

http://genesdev.cshlp.org/content/2/5/578.full.html\#ref-list-1

License

Email Alerting

Service

Receive free email alerts when new articles cite this article - sign up in the box at the top right corner of the article or click here. 